\title{
PERENCANAAN PERBAIKAN JTR PENYULANG SRLO01 DI DAERAH TANJUNGSARI GUNA MENGURANGI DROP TEGANGAN KONSUMEN PADA PT PLN (PERSERO) RAYON SEMARANG SELATAN MENGGUNAKAN SOFTWARE ETAP 12.6.0
}

\author{
Bambang Winardi ${ }^{*}$, Agung Nugroho, Dinda Hapsari Kusumastuti \\ Departemen Teknik Elektro, Universitas Diponegoro Semarang \\ Jl. Prof. Sudharto, SH, Kampus UNDIP Tembalang, Semarang 50275, Indonesia \\ *E-mail: bwundip@gmail.com
}

\begin{abstract}
Abstrak
Sambungan rumah adalah titik akhir dari pelayanan listrik kepada konsumen, sehingga potret pelayanan dapat dilihat dari mutu tegangan dan tingkat keandalan dari sisi sambungan rumah. Dalam hal ini penulis menemukan sebuah kasus nyata sampel di lapangan mengenai sambungan rumah yang tidak sesuai standar yang layak untuk dibahas dan direncanakan solusi perbaikan jaringannya. Jumlah tarikan sambungan rumah yang tidak standar ini menyebabkan tegangan rumah mengalami jatuh tegangan. Hasil pengukuran pada waktu beban puncak adalah $170 \mathrm{~V}$, persentasenya adalah $22,72 \%$. Padahal tegangan jatuh yang diijinkan adalah maksimal $198 \mathrm{~V}$, persentasenya adalah $10 \%$. Dengan melihat keadaan yang terjadi di lapangan, maka direncanakan solusi untuk perbaikan jaringan. Dalam penelitian ini digunakan software ETAP 12.6.0 untuk simulasi jaringan eksisting, yang akan dibandingkan dengan hasil pengukuran di lapangan. Pada pengukuran jatuh tegangan secara langsung berupa $170 \mathrm{~V}$, sedangkan jatuh tegangan dengan menggunakan software ETAP 12.6.0 berupa $168 \mathrm{~V}$. Sedangkan pada rencana perbaikan jaringan, perhitungan yang dilakukan dengan menggunakan software ETAP 12.6.0 diperoleh persentase jatuh tegangan hanya berkisar antara 1,81\% - 3,63\%. Pada software ETAP 12.6.0 menunjukkan bahwa rencana perbaikan yang dilakukan sudah memenuhi standar. Hal ini terlihat dari kisaran persetase jatuh tegangan dari $9,09 \% 22.72 \%$ bisa menjadi $1,81 \%-3,63 \%$.
\end{abstract}

Kata kunci : tegangan jatuh, perbaikan jaringan, software ETAP 12.6.0

\begin{abstract}
Home connection is the end point of the electricity service to the consumer, so that the portrait of service can be seen from the quality of the voltage and the level of reliability from the side of the home connection. In this case the authors found a real sample case in the field of home connections that did not fit the standards that deserved to be discussed and planned for network repair solutions. The amount of non-standard connection of the house connection causes the house voltage to experience a voltage drop. The measurement result at peak load time is $170 \mathrm{~V}$, the percentage is $22.72 \%$. Whereas the allowable drop voltage is a maximum of $198 \mathrm{~V}$, the percentage is $10 \%$. By looking at the circumstances that occur in the field, then planned solutions for network repair. In this research used ETAP 12.6.0 software for simulation of existing network, which will be compared with result of measurement in field. On the measurement of direct voltage drop of $170 \mathrm{~V}$, while the voltage drop using ETAP 12.6.0 software is $168 \mathrm{~V}$. While in the network repair plan, the calculations performed using ETAP 12.6.0 software obtained the percentage of voltage drops only ranged between 1.81 $\%-3.63 \%$. In the software ETAP 12.6.0 shows that the improvement plan has met the standards. This can be seen from the percentage range of falling voltage from $9.09 \% 22.72 \%$ could be $1.81 \%-3.63 \%$.
\end{abstract}

Keyword : voltage drop, network improvement, software ETAP 12.6.0

\section{Pendahuluan}

Masalah yang kerap dihadapi PT. PLN di bagian distribusi adalah tegangan yang sampai ke pelanggan mengalami jatuh tegangan atau tegangan turun di bawah standarisasi dari $\mathrm{PLN}^{7)}$. Pengaturan tegangan dan turun tegangan menurut SPLN No.72 Tahun $1987^{15}$ ) yaitu jatuh tegangan pada Jaringan Tegangan Menengah (JTM) maksimal 5\%, jatuh tegangan pada trafo maksimal 3\%, jatuh tegangan pada Jaringan Tegangan Rendah (JTR) maksimal 4\%, dan jatuh tegangan pada Saluran pelayanan (SLP) maksimal $1 \% .^{17)}$

Salah satu daerah yang pernah mengalami jatuh tegangan adalah daerah Tanjungsari, Kelurahan Sumurboto, 
Kecamatan Banyumanik, Semarang. Permasalahan tersebut diperoleh dari keluhan pelanggan yang melaporkan tegangannya di bawah 200 Volt. Hasil survey yang dilakukan, telah mendapat hasil bahwa salah satu tarikan di tiang terakhir di daerah Tanjungsari IV yang memiliki tarikan sambungan rumah (SR) melebihi batas yang diberikan dari PT. PLN, yaitu sejumlah 21 rumah. Besar tegangan pada ujung tarikan tersebut adalah 170 Volt yang diukur pada saat WBP (Waktu Beban Puncak).

Dari kasus tersebut, penulis akan memberikan rencana untuk memperbaiki JTR (Jaringan Tegangan Rendah) tersebut yaitu dengan memperluas jaringan. Dalam melakukan rencana perbaikan jatuh tegangan penulis menghitung jatuh tegangan dan mensimulasikan data yang ada dengan menggunakan software ETAP 12.6.0 kemudian melakukan rencana perbaikan jatuh tegangan di wilayah Tanjungsari tersebut dan kemudian mensimulasikannya dengan menggunakan software ETAP 12.6.0., ${ }^{\text {,9) }}$

\section{Metode}

\subsection{Data yang Dikumpulkan}

Metode pengumpulan data adalah proses dalam pencarian data. Dalam penelitian ini pengumpulan data dilakukan dari survey data langsung ke lokasi studi kasus yaitu di Jalan Tanjungsari, Kelurahan Sumurboto, Kecamatan Banyumanik, Kota Semarang. Data yang dibutuhkan adalah sebagai berikut :

1. Gambar Jaringan Eksisting Lokasi Studi Kasus

2. Panjang Jaringan

3. Daya Tersambung Tiap Konsumen

4. Tegangan yang mengalir pada LWBP dan WBP

\subsection{Kondisi Jaringan Eksisting}

Kondisi jaringan eksisting di lapangan yang terletak di Jalan Tanjungsari, Kelurahan Sumurboto, Kecamatan Banyumanik, Kota Semarang ini diambil dari trafo 50 KVA yang terhubung dengan JTR.

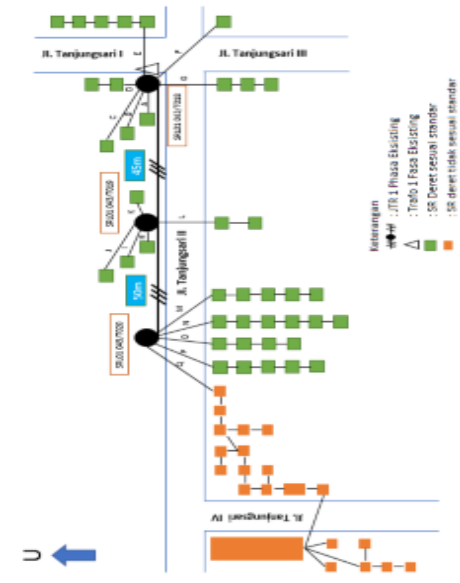

Gambar 1. Kondisi Jaringan Eksisting

\subsection{Data Jaringan Eksisting}

Tabel 1. Tegangan Pelayanan

\begin{tabular}{cccc}
\hline $\begin{array}{c}\text { Nomor } \\
\text { Tiang }\end{array}$ & Tarikan & $\begin{array}{c}\text { Tegangan } \\
\text { Pangkal }\end{array}$ & $\begin{array}{c}\text { Tegangan } \\
\text { Ujung }\end{array}$ \\
\hline & $\mathrm{A}$ & $220 \mathrm{~V}$ & $220 \mathrm{~V}$ \\
& $\mathrm{~B}$ & $219,6 \mathrm{~V}$ & $219,6 \mathrm{~V}$ \\
SRL01 & $\mathrm{C}$ & $218 \mathrm{~V}$ & 218 \\
043/T018 & $\mathrm{D}$ & $218 \mathrm{~V}$ & $215 \mathrm{~V}$ \\
& $\mathrm{E}$ & $217 \mathrm{~V}$ & $210 \mathrm{~V}$ \\
& $\mathrm{~F}$ & $218 \mathrm{~V}$ & $218 \mathrm{~V}$ \\
& $\mathrm{G}$ & $220 \mathrm{~V}$ & $214 \mathrm{~V}$ \\
& $\mathrm{H}$ & $215 \mathrm{~V}$ & $215 \mathrm{~V}$ \\
SRL01 & $\mathrm{I}$ & $214 \mathrm{~V}$ & $214 \mathrm{~V}$ \\
043/T019 & $\mathrm{J}$ & $213 \mathrm{~V}$ & $213 \mathrm{~V}$ \\
& $\mathrm{~K}$ & $215 \mathrm{~V}$ & $215 \mathrm{~V}$ \\
& $\mathrm{~L}$ & $216 \mathrm{~V}$ & $214 \mathrm{~V}$ \\
& $\mathrm{M}$ & $215 \mathrm{~V}$ & $213 \mathrm{~V}$ \\
SRL01 & $\mathrm{N}$ & $214 \mathrm{~V}$ & $211 \mathrm{~V}$ \\
043/T020 & $\mathrm{O}$ & $212 \mathrm{~V}$ & $209 \mathrm{~V}$ \\
& $\mathrm{P}$ & $212 \mathrm{~V}$ & $208 \mathrm{~V}$ \\
& $\mathrm{Q}$ & $210 \mathrm{~V}$ & $170 \mathrm{~V}$ \\
\hline
\end{tabular}

Dari tabel 1 di atas didapatkan bahwa pada tiang SRL01 043/T020 tarikan Q terjadi jatuh tegangan yang cukup besar sehingga tegangan pelayanan pada ujung sambungan rumah hanya 170 volt yang standarnya maksimal jatuh tegangan adalah 198 volt. Jatuh tegangan ini terjadi karena tarikan sambungan rumah tersebut tidak standar yaitu 21 tarikan yang standarnya hanya 5 tarikan. Jarak rumah terakhir dengan tiang pun cukup jauh yaitu 225 meter yang standarnya maksimal 150 meter.

Setelah melihat keadaaan ini maka penulis melakukan survey lapangan khususnya di tiang SRL01 043/T020 tarikan Q. Pada tarikan ini terdapat 7 pelanggan dengan daya $450 \mathrm{VA}, 9$ pelanggan daya $900 \mathrm{VA}, 3$ pelanggan daya 1300 VA, dan 1 pelanggan daya 4400 VA. Penulis melakukan survey lapangan dengan melakukan pengukuran tegangan dan mendapatkan tegangan pangkal $210 \mathrm{~V}$ pada pelanggan pertama dan mengalami jatuh tegangan 170 volt pada pelanggan ke 21. Adapun data pelanggan pada nomor tiang SRL01 043/T020 tarikan Q adalah sebagai berikut.

Tabel 2 Tegangan Pelayanan Tarikan Q

\begin{tabular}{lcc}
\hline \multicolumn{1}{c}{ ID Pelanggan } & $\begin{array}{c}\text { Daya } \\
\text { Terpasang }\end{array}$ & $\begin{array}{c}\text { Tegangan } \\
\text { Pelayanan }\end{array}$ \\
\hline $52-304-0259-496$ & $1300 \mathrm{VA}$ & $200 \mathrm{~V}$ \\
$52-304-0130-457$ & $450 \mathrm{VA}$ & $196 \mathrm{~V}$ \\
$52-304-0129-865$ & $450 \mathrm{VA}$ & $193 \mathrm{~V}$ \\
14027733352 & $900 \mathrm{VA}$ & $190 \mathrm{~V}$ \\
34024572751 & $1300 \mathrm{VA}$ & $189 \mathrm{~V}$ \\
$52-304-0130-196$ & $450 \mathrm{VA}$ & $185 \mathrm{~V}$ \\
$52-304-0621-874$ & $900 \mathrm{VA}$ & $185 \mathrm{~V}$ \\
$52-304-0294-021$ & $450 \mathrm{VA}$ & $185 \mathrm{~V}$ \\
$52-304-0284-747$ & $450 \mathrm{VA}$ & $183 \mathrm{~V}$ \\
$52-304-0130-041$ & $450 \mathrm{VA}$ & $180 \mathrm{~V}$ \\
$52-304-0130-806$ & $900 \mathrm{VA}$ & $179 \mathrm{~V}$ \\
32027772345 & $900 \mathrm{VA}$ & $177 \mathrm{~V}$ \\
$52-304-0415-111$ & $4400 \mathrm{VA}$ & $175 \mathrm{~V}$ \\
14020152154 & $900 \mathrm{VA}$ & $171 \mathrm{~V}$ \\
$52-304-0341-662$ & $2200 \mathrm{VA}$ & $173 \mathrm{~V}$ \\
\hline
\end{tabular}


Tabel 2. Lanjutan

\begin{tabular}{lcl}
\hline $52-304-0609-078$ & $900 \mathrm{VA}$ & $171 \mathrm{~V}$ \\
32029913327 & $900 \mathrm{VA}$ & $174 \mathrm{~V}$ \\
32030507779 & $1300 \mathrm{VA}$ & $174 \mathrm{~V}$ \\
45002871064 & $900 \mathrm{VA}$ & $173 \mathrm{~V}$ \\
$52-304-0416-461$ & $900 \mathrm{VA}$ & $173 \mathrm{~V}$ \\
$52-304-0177-277$ & $450 \mathrm{VA}$ & $170 \mathrm{~V}$ \\
\hline
\end{tabular}

\section{Hasil dan Analisa}

3.1. Simulasi Jaringan Eksisting dengan Software ETAP 12.6.0

Dari hasil simulasi dengan software ETAP tersebut dapat diperoleh jatuh tegangan pada masing- masing rumah. Jatuh tegangan hasil simulasi ETAP dapat dibandingkan dengan hasil pengukuran langsung seperti tabel di bawah ini.

Tabel 3. Perbandingan Jatuh Tegangan

\begin{tabular}{cccc}
\hline $\begin{array}{c}\text { Kode } \\
\text { Rumah }\end{array}$ & $\begin{array}{c}\text { Tegangan } \\
\text { Pelayanan } \\
\text { Pengukuran } \\
\text { Langsung }\end{array}$ & $\begin{array}{c}\text { Tegangan } \\
\text { Pelayanan } \\
\text { Simulasi ETAP }\end{array}$ & Selisih \\
\hline $\mathbf{1}$ & $200 \mathrm{~V}$ & $195 \mathrm{~V}$ & $5 \mathrm{~V}$ \\
$\mathbf{2}$ & $196 \mathrm{~V}$ & $191 \mathrm{~V}$ & $5 \mathrm{~V}$ \\
$\mathbf{3}$ & $193 \mathrm{~V}$ & $188 \mathrm{~V}$ & $5 \mathrm{~V}$ \\
$\mathbf{4}$ & $190 \mathrm{~V}$ & $187 \mathrm{~V}$ & $3 \mathrm{~V}$ \\
$\mathbf{5}$ & $189 \mathrm{~V}$ & $187 \mathrm{~V}$ & $2 \mathrm{~V}$ \\
$\mathbf{6}$ & $185 \mathrm{~V}$ & $183 \mathrm{~V}$ & $2 \mathrm{~V}$ \\
$\mathbf{7}$ & $185 \mathrm{~V}$ & $183 \mathrm{~V}$ & $2 \mathrm{~V}$ \\
$\mathbf{8}$ & $183 \mathrm{~V}$ & $183 \mathrm{~V}$ & $0 \mathrm{~V}$ \\
$\mathbf{9}$ & $180 \mathrm{~V}$ & $180 \mathrm{~V}$ & $0 \mathrm{~V}$ \\
$\mathbf{1 0}$ & $179 \mathrm{~V}$ & $177 \mathrm{~V}$ & $2 \mathrm{~V}$ \\
$\mathbf{1 1}$ & $177 \mathrm{~V}$ & $175 \mathrm{~V}$ & $2 \mathrm{~V}$ \\
$\mathbf{1 2}$ & $175 \mathrm{~V}$ & $175 \mathrm{~V}$ & $0 \mathrm{~V}$ \\
$\mathbf{1 3}$ & $171 \mathrm{~V}$ & $173 \mathrm{~V}$ & $2 \mathrm{~V}$ \\
$\mathbf{1 4}$ & $173 \mathrm{~V}$ & $172 \mathrm{~V}$ & $1 \mathrm{~V}$ \\
$\mathbf{1 5}$ & $171 \mathrm{~V}$ & $169 \mathrm{~V}$ & $2 \mathrm{~V}$ \\
16 & $174 \mathrm{~V}$ & $169 \mathrm{~V}$ & $5 \mathrm{~V}$ \\
$\mathbf{1 7}$ & $174 \mathrm{~V}$ & $169 \mathrm{~V}$ & $5 \mathrm{~V}$ \\
$\mathbf{1 8}$ & $173 \mathrm{~V}$ & $168 \mathrm{~V}$ & $5 \mathrm{~V}$ \\
19 & $173 \mathrm{~V}$ & $168 \mathrm{~V}$ & $5 \mathrm{~V}$ \\
$\mathbf{2 0}$ & $170 \mathrm{~V}$ & $168 \mathrm{~V}$ & $2 \mathrm{~V}$ \\
$\mathbf{2 1}$ & $170 \mathrm{~V}$ & $168 \mathrm{~V}$ & 2 \\
\hline & & & \\
& & & \\
\hline
\end{tabular}

\subsection{Perbandingan Persentase Jatuh Tegangan}

Dari hasil simulasi dengan software ETAP diperoleh persentase jatuh tegangan pada masing- masing rumah. Persentase jatuh tegangan hasil simulasi ETAP dapat dibandingkan dengan persentase jatuh tegangan hasil pengukuran langsung seperti tabel di bawah ini.

Tabel 4. Perbandingan Persentase DropTegangan

\begin{tabular}{cccc}
\hline $\begin{array}{c}\text { Kode } \\
\text { Rumah }\end{array}$ & $\begin{array}{c}\text { Persentase Jatuh } \\
\text { Tegangan } \\
\text { Pengukuran } \\
\text { Langsung }\end{array}$ & $\begin{array}{c}\text { Persentase } \\
\text { Jatuh } \\
\text { Tegangan } \\
\text { Simulasi ETAP }\end{array}$ & Selisih \\
\hline 1 & $9,09 \%$ & $11,36 \%$ & $2,27 \%$ \\
2 & $10,90 \%$ & $13,18 \%$ & $2,28 \%$ \\
3 & $12,27 \%$ & $14,54 \%$ & $2,27 \%$ \\
4 & $13,63 \%$ & $15 \%$ & $1,37 \%$ \\
5 & $14,09 \%$ & $15 \%$ & $0,91 \%$ \\
\hline
\end{tabular}

\begin{tabular}{cccc} 
Tabel 3. Lanjutan & & \\
\hline 6 & $15,90 \%$ & $16,81 \%$ & $0,91 \%$ \\
7 & $15,90 \%$ & $16,81 \%$ & $0,91 \%$ \\
8 & $16,81 \%$ & $16,81 \%$ & $0 \%$ \\
9 & $18,18 \%$ & $18,18 \%$ & $0 \%$ \\
10 & $18,63 \%$ & $19,54 \%$ & $0,91 \%$ \\
11 & $19,54 \%$ & $20,45 \%$ & $0,91 \%$ \\
12 & $20,45 \%$ & $20,45 \%$ & $0 \%$ \\
13 & $22,27 \%$ & $21,36 \%$ & $1,36 \%$ \\
14 & $21,36 \%$ & $21,81 \%$ & $0,45 \%$ \\
15 & $22,72 \%$ & $23,18 \%$ & $0,46 \%$ \\
16 & $20,90 \%$ & $23,18 \%$ & $2,28 \%$ \\
17 & $20,90 \%$ & $23,18 \%$ & $2,28 \%$ \\
18 & $21,36 \%$ & $23,63 \%$ & $2,27 \%$ \\
19 & $21,36 \%$ & $23,63 \%$ & $2,27 \%$ \\
20 & $22,72 \%$ & $23,63 \%$ & $0,91 \%$ \\
21 & $22,72 \%$ & $23,63 \%$ & $0,91 \%$ \\
\hline
\end{tabular}

\subsection{Perencanaan Perbaikan Jaringan Eksisting}

\section{Perluasan Jaringan Tegangan Rendah}

Perluasan jaringan tegangan rendah ini dilakukan dengan cara penambahan tiang. Penambahan tiang ini bertujuan untuk memperbaiki jumlah SR deret yang melebihi ketentuan PLN di lokasi studi kasus. Menurut Buku Standar Konstruksi Jaringan Distribusi yang diterbitkan oleh PLN, pada satu tiang JTR dapat disambung maksimal lima sambungan layanan pelanggan (SLP). Dalam satu SLP dapat disambung seri maksimum 5 sambungan rumah (5 SR). Sehingga dengan penambahan tiang ini akan dialihkan beberapa beban/pelanggan yang disuplai dari salah satu ujung line tiang JTR yang sambungannya tidak memenuhi standar PLN ke tiang JTR yang baru.

\section{Perluasan JTM Satu Fasa}

Langkah selanjutnya setelah penambahan kabel JTR adalah melakukan perluasan jaringan tegangan menengah satu fasa. JTM satu fasa yang baru akan berlokasi di tiang SRL01 043 T018 sampai dengan SRL01 043 T023. Perluasan JTM satu fasa ini sepanjang 210 meter.

Penghantar yang akan digunakan pada perluasaan JTM satu fasa ini adalah penghantar AAACS ukuran $35 \mathrm{~mm}^{2}$ yang merupakan penghantar berisolasi. Tujuan penggunaan penghantar jenis ini adalah untuk mengurangi resiko terhadap gangguan temporer khusunya gangguan yang disebabkan oleh pohon sehingga keandalan pasokan listrik di daerah ini akan terjamin.

\section{Penambahan Trafo Satu Fasa 50 KVA}

Trafo distribusi di lokasi studi kasus sudah overload, maka penambahan trafo satu fasa menjadi hal yang penting untuk memperbaiki jaringan di lokasi studi kasus. Trafo yang akan ditambahkan ini akan menampung 21.750 VA. Maka dari itu perlu ditambah trafo satu fasa dengan kapasitas 50 KVA. Penempatan trafo 1 fasa 50 KVA juga merupakan salah satu faktor yang sangat penting dalam memperbaiki tegangan. Hal ini dikarenakan 


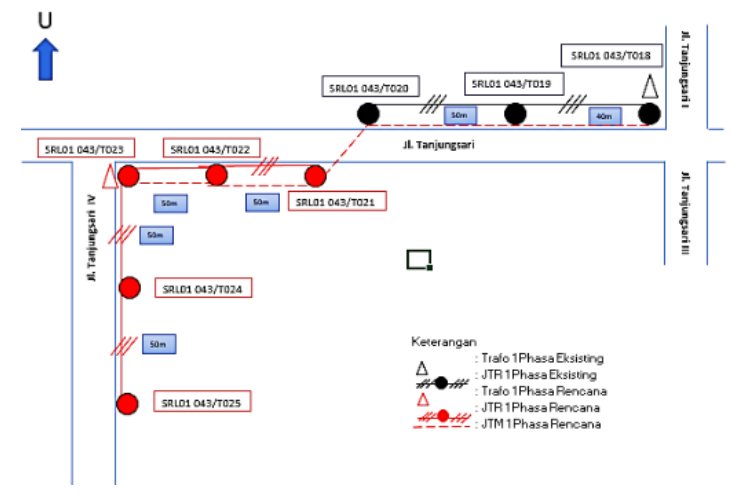

Gambar 2. Perencanaan Perluasan Jaringan Tegangan Rendah

semakin dekat dengan sumber tegangan, maka tegangan pada jaringan tersebut akan semakin baik. Oleh karena itu, trafo satu fasa $50 \mathrm{KVA}$ ini nantinya akan ditempatkan di tiang baru yaitu SRL01 043 T023. Kemudian jaringan yang menyuplai 21 rumah pada lokasi studi kasus ini akan displit atau dipisahkan dari jaringan awal sehingga 21 rumah ini nantinya akan disuplai dari trafo satu fasa $50 \mathrm{KVA}$ yang baru, dan 40 rumah akan disuplai dari trafo yang lama.

Selain itu trafo satu fasa $50 \mathrm{KVA}$ ini juga nantinya dapat mengantisipasi pertumbuhan beban di lokasi studi kasus. Seperti yang terlihat pada gambar jaringan eksisting menunjukan bahwa terdapat lahan kosong di sekitar lokasi studi kasus. Hal ini memberikan peluang untuk terjadinya pertumbuhan beban di lokasi tersebut.

\subsection{Perbaikan Tarikan Sambungan Rumah}

Perbaikan tarikan sambungan rumah sangat diperlukan untuk meminimalisir jatuh tegangan di jaringan eksisting lokasi studi kasus. Pada jaringan eksisting ini nantinya pada tarikan 21 rumah yang tidak standar akan dipindahkan ke tiang baru. Tarikan 21 rumah di lokasi studi kasus akan dipindahkan ke 5 tiang yang baru yang setiap tiang memiliki tarikan masing- masing.

Pada tiang SRL01 043 T021 akan ditarik 2 sambungan layanan pelanggan (SLP). SLP pertama terdiri dari 2 konsumen yaitu konsumen nomer 1 dan 2, sedangan SLP kedua terdiri dari 3 SLP, yaitu konsumen nomer 3, 4 dan 5. Pada tiang SRL01 043 T022 akan ditarik 2 SLP. SLP yang pertama dan kedua masing- masing terdiri dari 2 konsumen, yaitu nomer 78 dan 6 9. Pada tiang SRL01 043 023 ini tempat transformator 1 fasa diletakkan. Terdiri dari 2 tarikan SLP. SLP pertama dengan 1 konsumen nomer 10 dan SLP kedua dengan 2 konsumen nomer 11 dan 12. Pada tiang SRL01 043 T024 terdapat 2 SLP. SLP yang pertama terdiri dari 3 konsumen, yaitu nomer 15, 16 dan 17. SLP yang kedua terdiri dari 2 konsumen yaitu 13 dan 14. Pada tiang yang terakhir yaitu SRL01 043 T025 ditarik 2 tarikan SLP. SLP yang pertama terdiri dari konsumen nomer 18 dan 19. Sedangkan SLP yang kedua terdiri dari 2 SLP juga yaitu nomer 20 dan 21 .

Perbaikan tarikan sambungan rumah seperti yang telah dijelaskan di atas, akan digambarkan pada gambar 4.8 seperti gambar di bawah. Perbaikan tarikan sambungan rumah tersebut nantinya dapat memperbaiki kualitas tegangan karena sambungan rumah yang terpasang sudah sesuai standar PLN yaitu tarikan maksimal dari 1 SLP adalah 5 pelanggan.

\subsection{Kajian Kelayakan Jatuh Tegangan Menggunakan Simulasi software ETAP 12.6.0}

Simulasi kelayakan tegangan pelayanan menggunakan software ETAP 12.6.0 ini sama seperti simulasi software ETAP yang dilakukan sebelumnya pada jaringan eksisting lokasi studi kasus. Metode penggambaran tiang dan bus juga akan dilakukan sama seperti simulasi jaringan eksisting. Pembebanan sama seperti pembebanan pada saat dilakukan pengukuran tegangan di lokasi studi kasus. Sehingga dengan model pembebanan yang sama, rencana perbaikan jaringan ini dapat diketahui jatuh tegangannya.

Perbedaan gambar antara jaringan eksisting dan rencana perbaikan jaringan adalah adanya dua buah trafo satu fasa $50 \mathrm{KVA}$, adanya penambahan kabel LVTC pada jaringan rencana perbaikan dan adanya penataan sambungan rumah (SR) deret dimana satu sambungan layanan pelanggan hanya disambung maksimum lima rumah. Dan tentu saja hasil yang diharapkan pada simulasi rencana perbaikan jaringan ini adalah didapatkannya jatuh tegangan yang memenuhi standar sehingga rencana perbaikan yang telah dibuat ini layak untuk diterapkan dan dapat menjadi solusi dalam menangani kasus di Jalan Tanjungsari tersebut. Berikut adalah gambar single line diagram simulasi rencana perbaikan menggunakan software ETAP 12.6.0.

Dengan simulasi ETAP maka akan terlihat besarnya jatuh tegangan setelah dilakukanya perbaikan jaringan. Dan dengan menggunakan rumus persentase jatuh tegangan maka akan diketahui pula besarnya persentase jatuh tegangan.

\section{Kesimpulan}

Pada lokasi studi kasus, di Jalan Tanjungsari, Kelurahan Sumurboto, Kecamatan Banyumanik, Kota Semarang, terdapat salah satu tarikan di tiang SRL01 043 T020 mempunyai 21 tarikan. Padahal, standarnya adalah 5 tarikan. Jarak tiang terakhir sampai rumah ke 21 itu pun juga cukup jauh yaitu 200 meter yang standarnya hanya 150 meter.

Hasil pengukuran secara langsung menunjukkan bahwa jatuh tegangan di lokasi studi kasus yaitu dimulai dari rumah kedua. Besar jatuh tegangan di lokasi studi kasus berkisar antara $196 \mathrm{~V}-170 \mathrm{~V}$. Sedangkan dari perhitungan persentase jatuh tegangan antara 9,09\% - 22,72\%. 
Hasil perhitungan jatuh tegangan dengan menggunakan software ETAP berkisar antara $195 \mathrm{~V}-168 \mathrm{~V}$, sedangkan perhitungan persentase jatuh tegangan berkisar antara $11,36 \%-23,63 \%$.

Setelah dilakukan simulasi dengan menggunakan software $E T A P$, terdapat perbedaan tegangan antara hasil simulasi dengan pengukuran secara langsung. Selisih perhitungan jatuh tegangan secara langsung dengan menggunakan software ETAP hanya berkisar 0 - 5 Volt saja, sedangkan selisih perhitungan persentase jatuh tegangan secara langsung dengan menggunakan software ETAP $0 \%-2,28$ $\%$.

Untuk memperbaiki jatuh tegangan yang di bawah standar ini, maka penulis melakukan perbaikan pada jaringan. Perbaikan yang dilakukan adalah perluasan jaringan tegangan rendah (JTR). Perluasan JTR ini dilakukan karena jarak tiang terakhir dengan konsumen 21 jaraknya 200 meter, maka diperlukan penambahan JTR dengan penambahan tiang dan penambahan kabel JTR. Kemudian perluasan jaringan tegangan menengah (JTM) 1 fasa, yang digunakan untuk penempatan trafo satu fasa. Selain itu juga dilakukan penambahan transformator 1 fasa $50 \mathrm{kVA}$, yang akan menyuplai 21 rumah dengan total beban 21.750 VA. Penambahan trafo ini juga digunakan untuk mengatasi pertumbuhan beban di lokasi studi kasus. Dan yang paling penting dilakukan adalah penataan tarikan sambungan rumah pada tiang JTR yang baru ditambahkan.

Apabila perbaikan telah dilakukan maka perbaikan tersebut disimulasikan pada software ETAP 12.6.0. Dari simulasi ini terlihat bahwa perbaikan jaringan yang dilakukan layak untuk diterapkan, karena persentase jatuh tegangan berkisar antara $1,81 \%-3,63 \%$. Persentase jatuh tegangan tersebut sudah sesuai dengan standar PLN, yaitu SPLN No $1: 1995$ untuk drop tegangan maksimal 10\%.

\section{Referensi}

[1]. Anonim. 1992. Standard Konstruksi Jaringan Distribusi Di Lingkungan Perusahaan Listrik Negara, Buku saku. Jakarta : PT. PLN (Persero).

[2]. Anonim. 2006. Perhitungan Losses. Jakarta: Pusdiklat PT. PLN (Persero).

[3]. Anonim. 2009. Materi Prajabatan Bidang Distribusi : Desain Kriteria Jaringan Distribusi. Jakarta : Pusdiklat PT. PLN (Persero).

[4]. Anonim. 2010. Buku 1 : Kriteria Desain Enjiniring Konstruksi Jaringan Distribusi Tenaga Listrik . Jakarta : PT. PLN (Persero).
[5]. Anonim. 2010. Buku 3 : Standar Konstruksi Jaringan Tegangan Rendah Tenaga Listrik . Jakarta : PT. PLN (Persero).

[6]. Arumdina, Yulia. 2014. Perhitungan Prediksi Beban Listrik dari Tahun 2013 Hingga Tahun 2017 dengan Menggunakan Metode Regresi Linier Sederhana di PT. PLN (Persero) Rayon Semarang Tengah. Penelitian (tidak diterbitkan). Semarang : Universitas Diponegoro.

[7]. Kurniasih, Aisa Indra. 2013. Perencanaan Perbaikan Jaringan Dengan Perhitungan Losses Dan Simulasi Software Etap 7.5.0 Pada Sambungan Rumah Tidak Standar Di Perumahan Tlogosari Semarang. Penelitian (tidak diterbitkan). Semarang : Universitas Diponegoro.

[8]. Kurniawan, Deny Fluoriandi. 2014. Perbaikan Jaringan Tegangan Rendah dan Reposisi Trafo untuk Sambungan Rumah Pelanggan Guna Memperbaiki Jatuh Tegangan pada PT. PLN (Persero) Rayon Weleri. Penelitian (tidak diterbitkan). Semarang : Universitas Diponegoro.

[9]. Siregar. 2011. Study Perbaikan Faktor Daya Pada Sistem Radial $20 \mathrm{KV}$ Analisis Menggunakan Etap. Penelitian. Medan : Universitas Sumatra Utara.

[10]. Suartika, Made. 2010. Rekonfigurasi Jaringan Tegangan Rendah (JTR) Untuk Memperbaiki Drop Tegangan Di Daerah Banjar Tulangnyuh Klungkung. Jurnal Teknologi Elektro, Volume 9, Nomor 2. Bali : Universitas Udayana.

[11]. Sukmawidjaja, Maula. 2008. Perhitungan Profil Tegangan Pada Sistem Distribusi Menggunakan Matrix Admitansi Dan Matrix Impedansi Bus. Jurnal Teknik Elektro, Volume 7, Nomor 2, Jakarta : Universitas Trisakti.

[12]. Suswanto, Daman. 2009. Sistem Distribusi Tenaga Listrik. Makalah. Padang : Universitas Negeri Padang.

[13]. SPLN 54. 1984. Sambungan Listrik. Jakarta : Departemen Pertambangan dan Energi Perusahaan Umum Listrik Negara.

[14]. SPLN 56-1. 1993. Sambungan Listrik Tegangan Rendah (SLTR). Jakarta : Departemen Pertambangan dan Energi Perusahaan Umum Listrik Negara.

[15]. SPLN 72. 1987. Spesifikasi Desain untuk Jaringan Tegangan Menengah (JTM) dan Jaringan Tegangan Rendah (JTR). Jakarta : Departemen Pertambangan dan Energi Perusahaan Umum Listrik Negara.

[16]. SPLN 74. 1987. Standar Listrik Pedesaan. Jakarta : Departemen Pertambangan dan Energi Perusahaan Umum Listrik Negara.

[17]. SPLN 1. 1995. Tegangan-Tegangan Standar. Jakarta : Departemen Pertambangan dan Energi Perusahaan Umum Listrik Negara.

[18]. Wasis, Abraham Arif. 2014. Rekonfigurasi Jaringan Tegangan Rendah untuk Perbaikan Profil Tegangan dan Susut Daya Listrik di Desa Brumbung Kecamatan Mranggen Kabupaten Demak. Penelitian (tidak diterbitkan). Semarang : Universitas Diponegoro.

[19]. Zuhal. 2000. Dasar Teknik Listrik dan Elektronika Daya. Jakarta : Gramedia. 